

\section{Sumário}

UMA PERSPECTIVA COMPARADA ACERCA DA (NÃO) EFETIVIDADE DA DEMOCRACIA LOCAL NO BRASIL E EM Portugal. .................................................................................................... 12 Matheus Passos Silva

A “ATIVIDADE-AÇÃO” PUNITIVO-DISCIPLINAR. INTERATIVIDADE E COMPLEXIDADE ENTRE ATO, PROCEDIMENTO E PROCESSO ADMINISTRATIVO

Sandro Lucio Dezan e Paulo Afonso Cavichioli Carmona

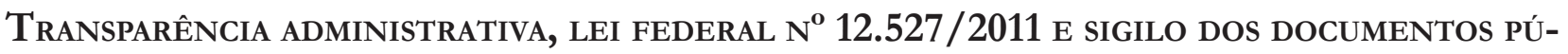
Blicos: A inconstitucionalidade dAS RESTRições AO ACESSO À INFORMAÇÃo....................46 Emerson Affonso da Costa Moura

A influência do Direito Administrativo Global no processo brasileiro de ContrataÇão Pública à luz do Princípio da Transparência .66 Alice Rocha da Silva e Ruth Maria Pereira dos Santos

Interna Corporis Acta e os limites do controle Judicial dos Atos legislativos..........90 Cintia Garabini Lages

A Releitura do PRINCíPIO dA ACTIO NATA QUANTO AOS DiREITOS DifUSOS NA JUDiCIALIZAÇÃo BRASILEIRA 105 Luiz Gustavo Gonçalves Ribeiro e Lorena Machado Rogedo Bastianetto

A Defensoria pública como garantia constitucional Processual de aCESSo À JustiÇa Na AMÉrica do Sul 117 Antonio Henrique Graciano Suxberger e Alberto Carvalho Amaral 
A política de assistênCia social e a promoção ao trabalho: uma ANÁlise do PRONATEC BSM COM BASE EM UM ESTUdo COM EgRESSOS EM ForTALEZA-CE

Aline de Araújo Araújo Martins e Mônica Duarte Cavaignac

INTERVENÇÃo ESTATAL NA AGRICULTURA: A POSSIBILIDADE DE UMA AÇão ÉTICA A FIM DE MATERIALIZAR A CONSTITUIÇÃO BRASILEIRA............................................................ 164

Davi Augusto Santana de Lelis e Giovani Clark

Agricultura orgânica: SOlUÇão Para o SÉCulo XXI? 185

Eloir Trindade Vasques Vieira, Denilson de Oliveira Guilherme, Luis Carlos Vinhas Itavo e Lucelia da Costa Nogueira Tashima

Os DESAFIos JURÍdicos E ECONÔMICOS DA AVIAÇão REgIONAL NO BRASIL

Pablo Leurquin e Mariana Magalhães Avelar

Homeschooling No Brasil: CONFORMAÇÃo DEÔNTICO-AXIOLÓGICA do SISTEMA JURÍdico COMO PLUS À POLÍTICA PÚBLICA DE EDUCAÇÃO FUNDAMENTAL.

Cláudio Márcio Bernardes, Giovani Clark

BARREIRAS À CIDADANIA NAS POlítiCAS SOCIAIS PARA A POPULAÇão EM SITUAÇÃo DE RUA........237 Luciano Roberto Gulart Cabral Júnior e José Ricardo Caetano Costa

O CORTE DO FORNECIMENTO DE ÁGUA EM FACE DO INADIMPLEMENTO DO CONSUMIDOR: ANÁLISE À LUZ DO DiÁlOGO DAS FonTES 251 Leonardo Roscoe Bessa e Gabriela Gomes Acioli César

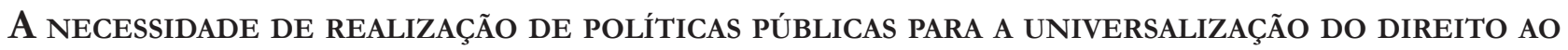
SANEAMENTO BÁSICO

Ruth Santos e Renata Menezes 


\title{
Os desafios jurídicos e econômicos da aviação regional no Brasil*
}

\section{The legal and economic challenges to the regional aviation in Brazil}

\author{
Pablo Leurquin** \\ Mariana Magalhães Avelar***
}

\section{Resumo}

Dada a capacidade de viabilizar a integração entre as regiões do país, o mercado de aviação civil é um setor da economia que tem relevante importância para o desenvolvimento brasileiro. A popularização do acesso ao serviço aéreo, desencadeada a partir dos anos 1990, contrastou com uma redução da quantidade de cidades abrangidas, o que revela uma deficiência de políticas econômicas voltadas ao desenvolvimento da aviação regional. $\mathrm{O}$ objetivo do presente estudo é apresentar uma síntese dos desafios jurídicos e econômicos da aviação regional no Brasil. Trata-se de pesquisa de cunho interdisciplinar, envolvendo reflexões, pesquisas e conceitos do Direito e da Economia. O artigo foi dividido em três seções. Na primeira, apresentam-se os motivos pelos quais a aviação regional deve ser considerada como um setor estratégico para o desenvolvimento econômico. Na segunda, apontam-se as possibilidades de intervenção do Estado nessa área. Na terceira, abordam-se os contornos políticos, jurídicos e econômicos do Programa Nacional de Aviação Regional.

Palavras-chave: Programa Nacional de Aviação Regional. Regulação do mercado de aviação civil. Desenvolvimento econômico.

* Recebido em 05/04/2016 Aprovado em 27/08/2016

** Doutorando em Direito Econômico pela Universidade Federal de Minas Gerais e em Direito Internacional e Europeu na Université Paris I, Panthéon-Sorbonne, com bolsa do CNPq e da CAPES/PSDE. Mestre em Direito Econômico pela Universidade Federal de Minas Gerais, financiado pelo CNPq. Bacharel em Direito pela Universidade Federal do Rio Grande do Norte. Pesquisador do Grupo de Pesquisa em Direito Econômico (GPDE) da FDUFMG. E-mail: pabloleurquin@yahoo.com.br

*** Mestranda em Direito e Administração Pública pela Universidade Federal de Minas Gerais. Especialista em Gestão e Finanças pela UFMG. Bacharel em Direito pela Universidade Federal de Minas Gerais. Advogada associada à sociedade de advogados Manesco, Ramires, Perez, Azevedo Marques. E-mail: mmagalhaesavelar@gmail.com.

\section{Abstract}

The airline market is very relevant to Brazilian economic development because of its ability to integrate several locations of the country. The increasing access to national airline services, build on the 1990's, contrasted with a major reduction on the cities covered by this kind of services and revealed that Brazilian regional aviation public policy is deficient. This study aims to present the legal and economic challenges to regional aviation in Brazil. The research reaches law and economic concepts, being divided in three sections. In the first one, it presents the reasons to considerate regional aviation as a strategic field to economic development. In the second section, it emphasizes the possibilities of state - mandated regulation on regional aviation. The third and last section presents the political, economic and legal aspects of the National Program of Regional Aviation, analyzing its effectiveness. 
Keywords: National Program of Regional Aviation. Airline market regulation. Economic development.

\section{INTRODUÇÃo}

A partir da década de 1990, a reorganização do modelo de intervenção do Estado no setor aéreo permitiu importantes benefícios, que giram em torno da popularização do serviço, ou seja, maior quantidade de pessoas sendo transportadas, menores preços das passagens aéreas e aumento na quantidade de voos. Entretanto, o principal aspecto negativo foi a redução substancial do número de cidades abrangidas com o serviço de aviação civil ${ }^{1}$.

No Brasil, bem como em outros países, o impulso desregulamentador do serviço aéreo redimensionou a estratégia das empresas prestadoras do serviço na medida em que induziu, por uma questão de economia de densidade, a concentração de suas atividades em menos cidades. Entretanto, apesar de algumas experiências de desregulamentação no exterior terem sido conjugadas com a valorização, por intermédio do Estado, da aviação regional, o Brasil não reproduziu esses exemplos e não realizou os devidos investimentos no setor da infraestrutura, muito menos na aviação regional.

Diante desse contexto, o presente trabalho tem como objetivo a apresentar os desafios jurídicos e econômicos para a expansão da aviação regional no Brasil. Para tanto, ele foi dividido em três seções. Na primeira serão apresentados o conceito de aviação regional e os pormenores de sua relevância para a universalização do serviço. Na segunda serão explorados os detalhes da contração da aviação regional brasileira, especialmente após o fim do Sistema Integrado de Transporte Aéreo Regional (SITAR), além disso, serão abordadas algumas propostas encontradas na literatura especializada sobre intervenções estatais para resolver o gargalo no setor. Por fim, serão apresentados os debates contemporâneos para a substancial implementação do Programa Nacional de Aviação Regional.

\section{RELEVÂNCIA dA AVIAÇão REGIONAL NA UNIVERSALIZAÇÃo do SERVIÇo}

Ao tratar da definição da aviação regional, costuma-se retomar a explicação de Humberto Bettini de atividade explorada de maneira regular, que realiza ligações entre cidades de baixa densidade de tráfego, utilizando-se de aeronaves de capacidade inferior a cem passageiros. Entretanto, trata-se de conceito difuso, pois suas fronteiras nem sempre são tão claras. O autor resgata, por exemplo, o fato de muitas vezes as empresas aéreas regionais operarem aeronaves com capacidade superior a cem lugares, como era o caso da TAM e Rio Sul, que utilizavam aviões Fokker F100 e Boeing 737-500, bem como a TABA, que contava com dois F100 em sua frota. Ainda sobre o aspecto difuso do conceito, destaca-se que as empresas regionais podem voar em cidades de elevada densidade de tráfego ou mesmo serem de porte nacional, servindo cidades de baixa densidade de tráfego, como ocorria em 2007 com a GOL, TAM e VARIG ou mesmo da Transbrasil e VASP, antes de encerrarem suas atividades. ${ }^{2}$

Nas palavras de Alessandro Oliveira e Lucia Helena Salgado, a característica mais marcante para definir a aviação regional é a avaliação do setor da incidência das economias de densidade. ${ }^{3} \mathrm{O}$ artigo "Economies of Density versus Economies of Scale: Why Trunk and Local Airline Costs Differ?” de Douglas Caves, Laurits

1 LEURQUIN, Pablo. Os impactos da regulação da aviação civil na integração inter-regional do Brasil. 2013. Dissertação (Mestrado) - Universidade Federal de Minas Gerais, Belo Horizonte, 2013. p. 68 e ss.

2 BETTINI, Humberto. Um retrato da aviação regional no Brasil. Journal of Transport Literature, v. 1, n. 1, p. 46-65, jan. 2007. Disponível em: <http://pesquisaemtransportes.net.br/relit/index.php/relit/article/viewFile/11/70>. Acesso em: 1 set. 2015 . p. 48.

3 OLIVEIRA, Alessandro; SALGADO, Lúcia Helena. Constituição do marco regulatório para o mercado brasileiro de aviação regional. abr. 2008. Disponível em: <http://pantanalbraziltourism.com/fotos/arquivos/96.pdf>. Acesso em: 1 set. 2015. p. 35. 
Christensen e Michael Tretheway, publicado em 1984, é considerado pela literatura da economia dos transportes como precursor na constatação de que, na aviação civil, a economia de densidade é mais relevante que a de escala. Em apertada síntese, os autores identificam que os custos médios são decrescentes conforme a etapa média ou o tamanho médio das aeronaves é maior. ${ }^{4}$

Portanto, de acordo com Humberto Bettini e Alessandro Oliveira, a partir dessa pesquisa, passou-se a entender que o maior custo dessas empresas não decorre de seu menor tamanho, mas de sua menor densidade de operações. Além disso, ficaram claros, também, os estímulos que esse tipo de empresa tem para adquirir aeronaves maiores, o que acaba diminuindo o custo do assento; e para voar trechos mais longos, o que reduz o custo por quilômetro. ${ }^{5}$

Dito isso, a partir da visão de Alessandro Oliveira e Lucia Helena Salgado, pode-se fazer quatro demarcações para delinear na prática o mercado de linhas regionais: a) com base na companhia aérea; b) com base na aeronave, que pode ser do tamanho normalmente menor de cem assentos; c) com base nos aeroportos, definidos a partir da movimentação de passageiros ou aeronaves ou das características do município, definição frequentemente empregada na legislação brasileira; e por fim d) com base na ligação aérea, na qual se leva em consideração a densidade do tráfego (até 15 mil passageiros por ano, por exemplo), trecho percorrido (até 1.000 quilômetros, por exemplo) e número de participantes. Todavia, os autores alertam que existe a possibilidade de ser adotado algum critério arbitrário no momento de segregar os mercados. Isso porque essa separação fica, ainda, mais complicada em um ambiente competitivo, calcado na liberdade, no momento de definir as trajetórias e a não regulamentação impedindo a entrada e saída de outras empresas. ${ }^{6}$

Apresentado o conceito de aviação regional, passa-se à análise da relevância desse setor do mercado para o desenvolvimento econômico. Para Frederico Turolla, Maria Fernanda Lima e Thelma Ohira, o transporte aéreo regional mitiga o isolamento territorial e inclui cidades em eixos de desenvolvimento econômico. Os autores destacam dois aspectos específicos: a) possibilidade de criação de concorrência no setor aéreo por meio do reforço da aviação regional; e b) geração de empregos e sustentação das diversas economias regionais. $^{7}$

Sobre o primeiro aspecto, sabe-se que a estrutura de mercado do setor aéreo brasileiro é caracterizada como oligopólio, o que não significa dizer que há obrigatoriamente baixa competição entre as empresas. ${ }^{8}$

Apesar disso, a literatura econômica identifica a possibilidade de surgimento, em um ambiente concentrado, de comportamentos colusivos, inclusive tácitos, ou até mesmo um processo de cartelização. A partir

4 Para mais informações sobre a pesquisa econométrica que permitiu a constatação que, quando se trata de aviação regional, a economia de densidade tem mais relevância que a de escala, ver: CAVES, Douglas; CHRISTENSEN, Laurits; TRETHEWAY, Michael. Economies of density versus economies of scale: why trunk and local airline costs differ? Rand Journal of Economics, v. 15, p. 471-489, 1984. Disponível em: <http://econpapers.repec.org/scripts/redir.pf?u=http\%3A\%2F\%2Flinks.jstor. org\%2Fsici\%3Fsici\%3D0741-6261\%2528198424\%252915\%253A4\%253C471\%253AEODVEO\%253E2.0.CO \%253B2-S\%26ori gin\%3Drepec;h=repec:rje:randje:v:15:y:1984:i:winter:p:471-489>. Acesso em: 1 set. 2015.

5 BETTINI, Humberto Filipe; OLIVEIRA, Alessandro V. M. Transporte aéreo regional: entre economias de escala e custos de transação. Journal of Transport Literature, v. 5, n. 4, p. 171-187, Oct. 2011. Disponível em: <https://www.google.com.br/url?sa-

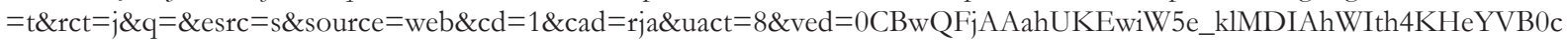
\&url $=\mathrm{http} \% 3 \mathrm{~A} \% 2 \mathrm{~F} \% 2 \mathrm{Fwww}$.pesquisaemtransportes.net.br $\% 2$ Frelit $\% 2$ Findex.php $\% 2 \mathrm{Frelit} \% 2 \mathrm{Farticle} \% 2 \mathrm{Fdownload} \% 2 \mathrm{Fjv} 5 \mathrm{n} 4 \mathrm{p}$ 10\%2F135\&usg=AFQjCNG1IqNxCI-1hoekrUSxBNxUymmI8Q\&sig2=ZPwA68Bu_OzMku67dsOwyg\&bvm=bv.104819420,d. dmo>. Acesso em: 1 set. 2015. p. 174.

6 OLIVEIRA, Alessandro; SALGADO, Lúcia Helena. Constituição do marco regulatório para o mercado brasileiro de aviação regional. abr. 2008. Disponível em: <http://pantanalbraziltourism.com/fotos/arquivos/96.pdf>. Acesso em: 1 set. 2015. p. 35.

7 TUROLLA, Frederico Araujo; LIMA, Maria Fernanda Freire; OHIRA, Thelma Harumi. Políticas públicas para a melhoria da competitividade da aviação regional brasileira. Journal of Transport Literature, v. 5, n. 4, p. 188-231, Oct. 2011. Disponível em: <http:// www.pesquisaemtransportes.net.br/relit/index.php/relit/article/view/jv5n4p11/pdf_57>. Acesso em: 1 set. 2015. p. 204.

8 Para mais detalhes sobre as concentrações mais recentes do setor, retomar: RUIZ, Ricardo Machado; HECKTHEUER, Leticiá Monteiro; BARROS, Gabriel Gil Barreto. Concentração e rivalidade em transporte aéreo de passageiros: reflexões a partir de casos recentes. In: SILVA, Leandro Novais (Org.) Regulação e concorrência no setor aéreo no Brasil: alternativas possíveis. São Paulo: Singular, 2014. p. 201-230. 
dessa visão, o fomento à entrada ou à redução das barreiras é estratégica para manter a competitividade no setor.

Portanto, tendo em vista que as companhias estabelecidas na aviação regional, por terem mais experiência na indústria específica, são entrantes mais prováveis dos mercados relevantes não regionais, elas têm importância inquestionável para a concorrência no setor. Diante disso, as possíveis desvantagens da aviação regional são minoradas dada essa importância na manutenção de possíveis entrantes nos mercados principais. ${ }^{9}$

Outro aspecto que Frederico Turolla, Maria Fernanda Lima e Thelma Ohira apresentam é a possibilidade da aviação regional de gerar empregos nas economias regionais. Essa perspectiva está ligada à possibilidade de evidenciar vocações regionais para negócios, que acabam ganhando maior espaço com um transporte que permita agilidade na locomoção de sujeitos e de cargas, em menor escala. ${ }^{10}$

Além desses pontos, questão que se mostra pertinente nesse contexto é a importância da aviação regional para a região amazônica. Nessa parte do território brasileiro, devido a suas caraterísticas geográficas, o sistema hidroviário é a principal rede física de transporte de cargas e de passageiros. Entretanto, as condições dessa locomoção, especialmente para os indivíduos, são precárias, além disso, determinados rios não são navegáveis durante todo o ano, devido às cheias e aos impedimentos decorrentes de bancos de areia, pedrais e travessões. Essas poucas condições de acessibilidade reforçam a necessidade de se consolidar o transporte aéreo como o principal na integração da própria região, bem como da mesma com as demais. ${ }^{11}$

Sobre a preocupação do desenvolvimento da aviação regional no Norte, em 2009, ainda durante o Governo do Presidente Lula, o Ministro Mangabeira Unger, da Secretaria de Assuntos Estratégicos, inseriu a intensificação da aviação regional na Amazônia, ao lado da construção de estradas vicinais e rodovias como uma das quatro etapas do Programa Amazônia Sustentável (PAS). ${ }^{12}$ Os outros eram a regularização ambiental, o surgimento do extrativismo madeireiro e não madeireiro, e a recuperação de áreas degradadas na Amazônia e no Cerrado. ${ }^{13}$

Isto posto, quando se pensa em investimento estatal no setor, o conceito de mercados de linhas essenciais chama atenção na temática da aviação regional. De acordo com Alessandro Oliveira e Lucia Helena Salgado, eles são caracterizados pela necessidade estratégica de garantir que esse serviço seja prestado. Como exemplo os autores citam localidades em área de fronteira, regiões inacessíveis sem outros meios de transportes, em zona rural ou turística, quando considerada serviço pioneiro. Às vezes essas linhas têm demanda futura suficiente para garantir seu sustento, entretanto, nos casos em que isso não se faz possível, o Estado costuma intervir. ${ }^{14}$

9 TUROLLA, Frederico Araujo; LIMA, Maria Fernanda Freire; OHIRA, Thelma Harumi. Políticas públicas para a melhoria da competitividade da aviação regional brasileira. Journal of Transport Literature, v. 5, n. 4, p. 188-231, Oct. 2011. Disponível em: < http:// www.pesquisaemtransportes.net.br/relit/index.php/relit/article/view/jv5n4p11/pdf_57>. Acesso em: 1 set. 2015 . p. 204.

10 TUROLLA, Frederico Araujo; LIMA, Maria Fernanda Freire; OHIRA, Thelma Harumi. Políticas públicas para a melhoria da competitividade da aviação regional brasileira. Journal of Transport Literature, v. 5, n. 4, p. 188-231, Oct. 2011. Disponível em: < http:// www.pesquisaemtransportes.net.br/relit/index.php/relit/article/view/jv5n4p11/pdf_57>. Acesso em: 1 set. 2015. p. 204 e ss.

11 BANCO NACIONAL DO DESENVOLVIMENTO. Aviação regional brasileira: modal aéreo IV. Informe infra-estrutura, n. 50, p. 7, 2002. Disponível em: <http://www.bndes.gov.br/SiteBNDES/export/sites/default/bndes_pt/Galerias/Arquivos/conhecimento/infra/Inf02-50.pdf>. Acesso em: 28 de ago. 2015.

12 Para ilustrar a importância que o Ministro Mangabeira Unger teve para fomentar o debate da aviação regional no Brasil, destacase que, na sua segunda posse como Ministro da Secretaria de Assuntos Estratégicos, em 2015, a Presidenta Dilma falou: "Todos os que integravam os ministérios ou órgão públicos naquela época sabem da contribuição do professor Mangabeira Unger. Destaco duas delas: o Plano Nacional de Defesa e a instigante determinação de que deveríamos investir em aeroportos regionais". INSTITUTO DE PESQUISA ECONÔMICA APLICADA. Mangabeira Unger toma posse como novo ministro da SAE. Brasília, 2 fev. 2015. Disponível em: <http://www.ipea.gov.br/portal/index.php?option=com_content\&view=article\&id=24432>. Acesso em: 2 set. 2015.

13 RÁDIO CÂMARA. Mangabeira Unger explica ações do governo para Amazônia e desenvolvimento regional. Câmara dos Deputados, Brasília, 10 mar. 2009. (3’57”). Disponível em: <http://www2.camara.leg.br/camaranoticias/radio/materias/ULTIMAS-NOTICIAS /364792-MANGABEIRA-UNGER-EXPLICA-A\%C3\%87\%C3\%95ES-DO-GOVERNO-PARAAMAZ\%C3\%94NIA-E-DESENVOLVIMENTO-REGIONAL-(03’57\%22).html>. Acesso em: 2 de set. 2015.

14 OLIVEIRA, Alessandro; SALGADO, Lúcia Helena. Constituição do marco regulatório para o mercado brasileiro de aviação regional. abr. 
Apesar da constatada necessidade de crescimento da aviação regional no Brasil, há deficiência histórica na formulação de políticas públicas para o setor. Esse comportamento é completamente diferente de outros países, em especial dos que possuem grandes extensões territoriais. Carlos Ragazzo e Cristiane Albuquerque, em seu texto "Concorrência e universalização: incentivos regulatórios à aviação regional", expõem algumas experiências internacionais de investimento estatal na aviação regional. Dentre elas merecem destaque duas nos EUA: o Programa de serviço aéreo essencial (Essential air service program), que passou a ser mais restrito após recentes reformulações; e o Programa de desenvolvimento de serviço aéreo de pequenas comunidades (Small community air service development program), criado em 2000, que concede linhas de crédito passíveis de financiar programas de marketing, contratação de pessoal e estudos em aeroportos. Em relação à União Europeia, por sua vez, no caso de nenhuma empresa ter interesse em atuar em uma rota considerada essencial para o desenvolvimento econômico da região (Regulação 1008/2008), o Estado-Membro pode restringir o acesso a apenas uma empresa no mercado específico por um período de no máximo quatro anos, ressarcindo seus prejuízos operacionais. ${ }^{15}$

No Brasil, frisa-se que a primeira política sistemática de investimento na aviação regional foi a Rede de Integração Nacional (RIN), instaurada em 1963. Tendo como objetivo subsidiar as empresas que trafegassem em rotas de baixo e médio potencial de tráfego e utilizassem aeronaves DC-3, Catalina ou C-46, com até 31 assentos, ela só durou até $1972 .{ }^{16}$ Em seguida, conforme visto na seção do capítulo 2 destinada ao histórico da regulação da aviação civil no Brasil, veio o SITAR. Após a extinção dele, a única medida que influenciava a aviação regional era o Programa Federal de Auxílio a Aeroportos (PROFAA), e que destinava $20 \%$ (percentual que subiu para 25,24\% em 2013) dos recursos originados do Adicional de Tarifas Aeroportuária (ATAERO) a aeroportos e aeródromos de interesse regional e estadual, conforme determinado pela Lei $n^{\circ} 8.399$, de 7 de janeiro de 1992.

Os recursos do programa eram frequentemente aplicados em razão de convênios, celebrados entre o Ministério da Defesa e entes gestores de aeródromos de interesse regional ou estadual. Apesar disso, conforme elucida Carlos Ragazzo e Cristiane Albuquerque, esse programa teve pouco efeito na manutenção da quantidade de cidades abrangidas pelo serviço aéreo. ${ }^{17}$

Ressalta-se em adendo a possível revogação da legislação que estabelece a destinação dos recursos acima mencionados ao PROFAA. Fala-se em possível revogação em vista da edição da Medida Provisória n ${ }^{\circ}$ 714, de $1^{\circ}$ de março de 2016, cujo art. $5^{\circ}$, II b) que estabelece a revogação, a partir de $1^{\circ}$ de janeiro de 2017 , da Lei no 8.399, de 7 de janeiro de 1992. Ao que tudo indica se agravará o quadro de ausência de investimentos intensivos na aviação regional ${ }^{18}$,

Esse quadro é especialmente gravoso ante o fato de que vários outros países cumularam a política de desregulamentação do setor aéreo com o investimento na aviação civil regional. Nesse cenário merece atenção a ausência desse tipo de postura do Estado brasileiro, que acabou por estagnar demasiadamente essa parte do mercado. Compreendida a importância da aviação regional para o desenvolvimento econômico do país, em especial para a universalização do serviço, passa-se à análise mais precisa da dimensão da contração desse mercado nos últimos anos.

2008. Disponível em: <http://pantanalbraziltourism.com/fotos/arquivos/96.pdf>. Acesso em: 1 set. 2015. p. 52.

15 Não se pretende com esse trabalho exaurir os pormenores das experiências estrangeiras de investimento Estatal no mercado de aviação regional, mas apenas dar notícia que se trata de realidade comum em outros países, como é o caso também da Austrália e Canadá, por exemplo. Para mais informações sobre o assunto, ver: RAGAZZO, Carlos Emmanuel Joppert; ALBUQUERQUE, Cristiane Landerdahl de. Concorrência e universalização: incentivos regulatórios à aviação regional. In: SILVA, Leandro Novais (Org.). Regulação e concorrência no setor aéreo no Brasil: alternativas possíveis. São Paulo: Singular, 2014. p. 238 e ss.

16 PINTO, Victor Carvalho. Dirigismo versus livre-iniciativa na regulação econômica do transporte aéreo. In: SILVA, Leandro Novais (Org.). Regulação e concorrência no setor aéreo no Brasil: alternativas possíveis. São Paulo: Singular, 2014. p. 37.

17 RAGAZZO, Carlos Emmanuel Joppert; ALBUQUERQUE, Cristiane Landerdahl de. Concorrência e universalização: incentivos regulatórios à aviação regional. In: SILVA, Leandro Novais (Org.). Regulação e concorrência no setor aéreo no Brasil: alternativas possíveis. São Paulo: Singular, 2014. p. 235.

18 Ao que tudo indica crescerá a importância do Fundo Nacional de Aviação Civil na realização de investimentos dependerá na atuação de investimento. A atuação do referido fundo será discriminada adiante. 


\section{A CONTRAÇÃo DA AVIAÇÃo REGIONAL BRASILEIRA E A NECESSIDADE DA INTERVENÇÃo ESTATAL}

Alessandro Oliveira e Lucia Helena Salgado retomam os dados do Anuário Estatístico da ANAC para afirmar que o crescimento no número de passageiros-quilômetros pagos foi de 22,5\% somente em 2010. Segundo eles, trata-se de "taxas chinesas" de crescimento, ${ }^{19}$ que colocam o Brasil como um dos países em que a aviação civil mais cresceu. Entretanto, esses indicadores não ressoam nas análises da aviação regional. Na realidade, de acordo com os mesmos, ela vem apresentando claros sinais de contração. ${ }^{20}$

Além disso, os autores apontam que houve crescimento de 6\% no número de ligações, o que pode ser considerado abaixo do esperado se for levado em consideração o rápido crescimento do setor na última década. Atrelado a isso, praticamente um terço das ligações não alcançou sustentabilidade e isso pode ilustrar o tamanho da vulnerabilidade do setor. Assim, para Alessandro Oliveira e Lucia Helena Salgado, pode-se concluir que há um "importante gargalo aeroportuário concentrado não apenas nos grandes centros, mas também ao longo do território nacional, nos pequenos e médios aeroportos que deixaram de ser servidos". ${ }^{21}$

Dados de 2012 fornecidos pela Associação Brasileira das Empresas Aéreas (ABEAR) reforçam a má distribuição do transporte aéreo, pois informam que dos 98 aeroportos brasileiros (administrados pela INFRAERO ou DAESP) 18 estão localizados em regiões com mais de 5 milhões de passageiros; 24 em regiões com 1 a 5 milhões de passageiros; e 56 em regiões com até 1 milhão de passageiros. Entretanto, a maior parte dos passageiros se concentra em regiões com mais de 5 milhões de passageiros. Além disso, esse estudo mostrou que dos doze maiores aeroportos do país, oito já estão com utilização igual ou acima da capacidade reportada, que é o caso de Guarulhos, Congonhas, Brasília, Rio de Janeiro, Belo Horizonte, Rio de Janeiro, Salvador, Porto Alegre, Campinas, Recife e Fortaleza. ${ }^{22}$

Humberto Bettini e Alessandro Oliveira destacam que, entre 1998 e 2008, houve redução de 199 para 155 cidades abrangidas pelo transporte aéreo regular. Os autores afirmam também que, na primeira metade da década de 2000, as empresas aéreas regionais transportaram uma parcela muito restrita dos passageiros domésticos totais (volumes entre 2,5\% e 4,5\%), sem contar que a situação financeira era extremamente instável, como pode ser visto na quantidade de encerramento de operações de empresas que se mantiveram durante muito tempo equilibradas, como a AirMinas, Penta, Rico e TAF. Os indicadores de lucratividade, por sua vez, não deixaram de se mostrar menores até mesmo para a Trip Linhas Aéreas, que era a líder da aviação regional em 2011.23

No que tange à instabilidade das empresas aéreas regionais, pode-se identificar o processo de incorporação desse tipo de empresa por outras como um sintoma da fragilidade do setor. A compra da Pantanal pela TAM Linhas Aéreas, em 2009, ilustra bem esse processo. Essa aquisição ganha especial relevância se for levado em consideração que a TAM já havia realizado pelo menos cinco movimentos progressivos de abandono da exploração do negócio da aviação regional por conta própria. Desperta atenção, também, por

19 A metáfora torna-se, no mínimo, curiosa se forem levados em consideração os dados da economia chinesa em 2015.

20 Cf. OLIVEIRA, Alessandro; SALGADO, Lúcia Helena. Popularização do transporte aéreo no Brasil: onde falta avançar nas políticas públicas? In: SILVA, Leandro Novais (Org.). Regulação e concorrência no setor aéreo no Brasil: alternativas possíveis. São Paulo: Singular, 2014. p. 298.

21 OLIVEIRA, Alessandro; SALGADO, Lúcia Helena. Popularização do transporte aéreo no Brasil: onde falta avançar nas políticas públicas? In: SILVA, Leandro Novais (Org.). Regulação e concorrência no setor aéreo no Brasil: alternativas possíveis. São Paulo: Singular, 2014. p. 299.

22 ASSOCIAÇÃO BRASILEIRA DAS EMPRESAS AÉREAS. Aviação brasileira: Agenda 2020, Brasília: ABEAR, 2014. Disponível em: <http://www.abear.com.br/uploads/pdf/releases/agenda2020.pdf>. Acesso em: 2 set. 2015. p. 29-30.

23 BETTINI, Humberto Filipe; OLIVEIRA, Alessandro V. M. Transporte aéreo regional: entre economias de escala e custos de transação. Journal of Transport Literature, v. 5, n. 4, p. 171-187, Oct. 2011. Disponível em: <https://www.google.com.br/url?sa$=\mathrm{t} \& \mathrm{rct}=\mathrm{j} \& \mathrm{q}=\& \mathrm{esrc}=\mathrm{s} \&$ source $={ }_{\mathrm{web}} \& \mathrm{~cd}=1 \& \mathrm{cad}=\mathrm{rja} \& u a c t=8 \& \mathrm{ved}=0 \mathrm{CBwQFjAAahUKEwiW5e \_ klMDIAhWIth4KHeYVB0c}$ \&url $=\mathrm{http} \% 3 \mathrm{~A} \% 2 \mathrm{~F} \% 2 \mathrm{Fwww}$.pesquisaemtransportes.net.br $\% 2$ Frelit $\% 2$ Findex.php $\% 2 \mathrm{Frelit} \% 2 \mathrm{Farticle} \% 2 \mathrm{Fdownload} \% 2 \mathrm{Fjv} 5 \mathrm{n} 4 \mathrm{p}$ 10\%2F135\&usg=AFQjCNG1IqNxCI-1 hoekrUSxBNxUymmI8Q\&sig2=ZPwA68Bu_OzMku67dsOwyg\&bvm=bv.104819420,d. dmo>. Acesso em: 1 set. 2015. p. 174. 
ter sido a primeira vez que uma empresa aérea de porte nacional voltou a ser proprietária de uma de natureza regional. ${ }^{24}$

A preocupação concorrencial com esse tipo de comportamento é informada por Frederico Turolla, Maria Fernanda Lima e Thelma Ohira, ao sustentar que apesar da alimentação das empresas regionais interessar às principais, o fato de estas serem potenciais concorrentes pode instigá-las a assumirem comportamentos de predação do tipo bit-and-run. ${ }^{25}$

Uma possibilidade levantada por Humberto Bettini e Alessandro Oliveira para justificar esse movimento foi fundada na necessidade de aquisição de novos slots no aeroporto já congestionado de Congonhas. Entretanto, o fato de a TAM ter mantido a unidade de negócios Pantanal e que até mesmo a sua frota seria renovada e expandida foi interpretado com estranheza pelos pesquisadores. De toda sorte, os autores consideraram esse movimento da TAM como um sinal mais forte da erosão do sistema bub-and-spoke $e^{26}$, aliado à interiorização do transporte aéreo e a necessidade de reforço da marca junto aos consumidores. ${ }^{27}$

Os desafios para as empresas são de diversas naturezas, como apontam vários estudos. Dentre eles, pode-se destacar o realizado por Frederico Turolla, Maria Fernanda Lima e Thelma Ohira, que identificam sete problemas mais relevantes: o preço dos combustíveis; a infraestrutura aeroportuária; os custos com pessoal; o regime de recolhimento da tributação; as taxas regulatórias; os seguros, os custos de capital e financiamento; e a manutenção das aeronaves. A partir desse momento, cada um desses gargalos será brevemente apresentado em conjunto com possíveis soluções são apresentadas por teóricos dessa temática.

O primeiro deles é o combustível, que é apontado na segunda posição entre os maiores custos para as empresas, pois representa de $20 \%$ a $40 \%$ dos custos diretos operacionais das companhias aéreas. Essa situação se agrava na aviação regional porque sua malha é planejada com um número menor de revendedores e distribuidores de combustível, o que leva a uma redução do espaço para este usufruir da concorrência decorrente dos diferentes ICMS existentes entre fornecedores localizados em estados diferentes. Além disso, os equipamentos utilizados na aviação regional normalmente consomem mais combustível.

Os principais tributos que incidem no preço do combustível de aviação são ICMS (estadual), PIS/ PASEP (federal) e COFINS (federal). Na tentativa de favorecer a aviação regional, os autores sugerem desoneração adicional ao PIS/PASEP e COFINS, no sentido de zerar o coeficiente de 0,7405. Além disso, se poderiam reduzir para zero os valores por metro cúbico da COFINS e do PIS/PASEP no caso da alíquota específica. Outra possibilidade apresentada é reduzir a alíquota do ICMS a 4\% para voos de linhas regionais ou para aeroportos que não sejam de capitais. ${ }^{28}$

24 BETTINI, Humberto Filipe; OLIVEIRA, Alessandro V. M. Transporte aéreo regional: entre economias de escala e custos de transação. Journal of Transport Literature, v. 5, n. 4, p. 171-187, Oct. 2011. Disponível em: <https://www.google.com.br/url?sa-

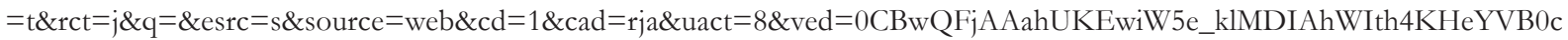
\&url $=$ http $\% 3 \mathrm{~A} \% 2 \mathrm{~F} \% 2 \mathrm{Fwww}$.pesquisaemtransportes.net.br $\% 2$ Frelit $\% 2$ Findex.php $\% 2$ Frelit $\% 2$ Farticle $\% 2 \mathrm{Fdownload} \% 2 \mathrm{Fjv} 5 \mathrm{n} 4 \mathrm{p}$ 10\%2F135\&usg=AFQjCNG1IqNxCI-1hoekrUSxBNxUymmI8Q\&sig2=ZPwA68Bu_OzMku67dsOwyg\&bvm=bv.104819420,d. dmo>. Acesso em: 1 set. 2015. p. 176.

25 TUROLLA, Frederico Araujo; LIMA, Maria Fernanda Freire; OHIRA, Thelma Harumi. Políticas públicas para a melhoria da competitividade da aviação regional brasileira. Journal of Transport Literature, v. 5, n. 4, p. 188-231, Oct. 2011. Disponível em: <http:// www.pesquisaemtransportes.net.br/relit/index.php/relit/article/view/jv5n4p11/pdf_57>. Acesso em: 1 set. 2015 . p. 204.

26 O sistema centro-raio (bub-and-spoke system) se fundamenta na existência de um aeroporto bem localizado e com importante ponto de geração de tráfego, conectado aos demais aeroportos, que concentram os voos e distribuem as ligações para aeroportos menores.

27 BETTINI, Humberto Filipe; OLIVEIRA, Alessandro V. M. Transporte aéreo regional: entre economias de escala e custos de transação. Journal of Transport Literature, v. 5, n. 4, p. 171-187, Oct. 2011. Disponível em: <https://www.google.com.br/url?sa-

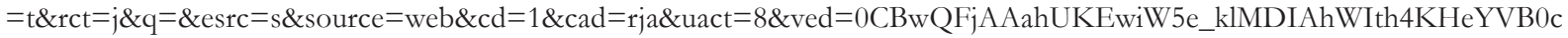
\&url=http $\% 3 \mathrm{~A} \% 2 \mathrm{~F} \% 2 \mathrm{Fwww}$.pesquisaemtransportes.net.br $\% 2$ Frelit $\% 2$ Findex.php $\% 2$ Frelit $\% 2$ Farticle $\% 2 \mathrm{Fdownload} \% 2 \mathrm{Fjv} 5 \mathrm{n} 4 \mathrm{p}$ 10\%2F135\&usg=AFQjCNG1IqNxCI-1hoekrUSxBNxUymmI8Q\&sig2=ZPwA68Bu_OzMku67dsOwyg\&bvm=bv.104819420,d. dmo>. Acesso em: 1 set. 2015. p. 174.

28 TUROLLA, Frederico Araujo; LIMA, Maria Fernanda Freire; OHIRA, Thelma Harumi. Políticas públicas para a melhoria da competitividade da aviação regional brasileira. Journal of Transport Literature, v. 5, n. 4, p. 188-231, Oct. 2011. Disponível em: <http:// 
O segundo gargalo para a aviação regional identificado pelos autores é a infraestrutura aeroportuária, que também é preocupação de Marcos Demant. Ele argumenta no sentido de que se trata de uma barreira à entrada de empresas regionais e constrói a hipótese de que cidades com melhores infraestrutura tendem a apresentar maior tráfego. ${ }^{29} \mathrm{O}$ autor identifica que o estrangulamento da infraestrutura também impede o desenvolvimento da aviação regional e que se faz necessária uma política pública voltada à solução desse problema. Carlos Ragazzo critica o modelo centralizado da INFRAERO e sugere que haja mais concessões para a iniciativa privada ou mesmo parcerias com os estados e municípios. ${ }^{30}$

Frederico Turolla, Maria Fernanda Lima e Thelma Ohira avaliam que a legislação trabalhista é um custo que tem impacto diferente de acordo com o tamanho da empresa. Além disso, existe um padrão que se repete na referida indústria, que é o fato de as empresas regionais terem baixo incentivo para qualificar a tripulação técnica, pois estes, após formados, tendem a ir trabalhar nas empresas principais. Os autores citam, também, o suposto alto custo das diárias, sugerindo que haja uma diminuição de custos com o pessoal. ${ }^{31}$ Apesar de reconhecer a importância dos argumentos dos autores, acredita-se que esse tipo de argumento pode colocar em piores condições o trabalhador, já submetido a atividade que, devido a seu alto risco, é extremamente estressante; isso pode significar, em última instância, um retrocesso dos direitos sociais. $^{32}$

Os referidos autores sugerem, também, a criação de um sistema análogo ao SIMPLES (regime especial unificado de arrecadação de tributos e contribuições devidos pelas microempresas e empresas de pequeno porte, instituído pela Lei Complementar n ${ }^{\circ} 123$, de 2006). Eles sugerem que as empresas de aviação regional paguem o conjunto de tributos por intermédio de uma alíquota única de 4,5\% sobre o faturamento. ${ }^{33}$

Embora inexistam grandes ações de simplificação tributária, existem algumas medidas de incentivo, como a estabelecida pela Lei $\mathrm{n}^{\circ}$ 11.488, de 15 de junho de 2007, que cria o Regime Especial de Incentivos para o Desenvolvimento da Infraestrutura - REIDI, regulamentada pelo Decreto no 6.144 de 3 de julho de 2007. No que tangencia os projetos de infraestrutura em aviação, referida legislação foi regulamentada pela Portaria SAC no 18, de 23 de janeiro de 2012, que disciplina os requisitos mínimos para a aprovação de projetos de investimento na área de infraestrutura, considerados prioritários no setor de Aviação Civil, bem como pela Portaria SAC no 93, de 6 de julho de 2012, que estabelece o procedimento de aprovação dos projetos de implantação de obras de infraestrutura nos sistemas aeroportuários e de proteção ao voo, instalados em aeródromos públicos, para fins de habilitação ao REIDE.

www.pesquisaemtransportes.net.br/relit/index.php/relit/article/view/jv5n4p11/pdf_57>. Acesso em: 1 set. 2015 . p. 204.

29 Cf. DEMANT, Marcos Alexandre. Infraestrutura aeroportuária e o desenvolvimento do tráfego aéreo regional no Brasil. Journal of Transport Literature, v. 5, n. 1, p. 124-160, Jan. 2011. Disponível em: <https:/ /www.google.com.br/url?sa=t\&rct=j\&q=\&e $\mathrm{src}=\mathrm{s} \&$ source $=$ web\&cd $=1 \& \mathrm{cad}=$ rja\&uact $=8 \& \mathrm{ved}=0 \mathrm{CBwQFjAAahUKEwiCkceZn} 8 \mathrm{DIAhWIVh} 4 \mathrm{KHa} 1 \mathrm{XAQs} \& u r \mathrm{l}=\mathrm{http} \% 3 \mathrm{~A} \%$ $2 \mathrm{~F} \% 2 \mathrm{Fwww}$.pesquisaemtransportes.net.br $\% 2 \mathrm{Frelit} \% 2 \mathrm{Findex} \cdot \mathrm{php} \% 2 \mathrm{Frelit} \% 2 \mathrm{Farticle} \% 2 \mathrm{Fdownload} \% 2 \mathrm{Fj} v 5 \mathrm{n} 1 \mathrm{p} 7 \% 2 \mathrm{~F} 83 \& \mathrm{usg}=\mathrm{AF}$ QjCNEodE0Mg9BV9erZMWira_tijZVSjw\&sig2=FuuWkoz1LyJhSso3xW4bOw\&bvm=bv.104819420,d.dmo>. Acesso em: 1 set. 2015. p. 154.

30 RAGAZZO, Carlos Emmanuel Joppert; ALBUQUERQUE, Cristiane Landerdahl de. Concorrência e universalização: incentivos regulatórios à aviação regional. In: SILVA, Leandro Novais (Org.). Regulação e concorrência no setor aéreo no Brasil: alternativas possíveis. São Paulo: Singular, 2014. p. 249.

31 TUROLLA, Frederico Araujo; LIMA, Maria Fernanda Freire; OHIRA, Thelma Harumi. Políticas públicas para a melhoria da competitividade da aviação regional brasileira. Journal of Transport Literature, v. 5, n. 4, p. 188-231, Oct. 2011. Disponível em: < http:// www.pesquisaemtransportes.net.br/relit/index.php/relit/article/view/jv5n4p11/pdf_57>. Acesso em: 1 set. 2015 . p. 204.

32 Esse ponto ganha destaque com as últimas manifestações contra as demissões em massa anunciadas pela Air France. De acordo com a mesma 300 pilotos, 900 comissários e 1,7 mil funcionários de apoio em terra poderão ter seus cargos cortados. Essa decisão decorreu do fato dos sindicatos representantes da tripulação não aceitarem aumentar a quantidade de hora de trabalho sem a devida remuneração. ROSEMAIN, Mathieu. Grevistas agridem executivos da Air France. Valor Econômico, São Paulo, 6 out. 2015. Disponível em: <http://www.valor.com.br/empresas/4257122/grevistas-agridem-executivos-da-air-france>. Acesso em: 8 out. 2015.

33 TUROLLA, Frederico Araujo; LIMA, Maria Fernanda Freire; OHIRA, Thelma Harumi. Políticas públicas para a melhoria da competitividade da aviação regional brasileira. Journal of Transport Literature, v. 5, n. 4, p. 188-231, Oct. 2011. Disponível em: <http:// www.pesquisaemtransportes.net.br/relit/index.php/relit/article/view/jv5n4p11/pdf_57>. Acesso em: 1 set. 2015. p. 218 . p. 204. 
Outro ponto importante é a necessidade de redução ou isenção de taxas aeroportuárias em aeroportos regionais. De acordo com Carlos Ragazzo, até mesmo reduções e isenções de impostos aplicados às tarifas de passagens aéreas poderiam ser um possível incentivo a ser feito pelo Estado. Trata-se de uma estratégia adotada pelos EUA para os aeroportos rurais. Já a Austrália congelou as tarifas do aeroporto de Sidney para empresas regionais. ${ }^{34}$

Consta da agenda regulatória da ANAC, instituída pela Portaria no 160 de 26 de janeiro de 2016, uma tímida mudança na forma de cobrança de taxas em aeroportos regionais, a partir na sinalização da descentralização da regulação tarifária aplicável aos aeroportos conveniados nos Estados e Municípios. A agência objetiva com tal meta propor normatização que estabeleça regime tarifário diferenciado aplicável aos aeroportos administrados, por meio de convênio, por estados e municípios. O objetivo é permitir que administradores/reguladores locais (estados e municípios) busquem formas mais eficientes de remuneração das infraestruturas delegadas.

Outro problema comum é o manejo de riscos da atividade em aeroportos regionais e a adoção de medidas de prevenção e mitigação, em especial dos seguros. Costuma-se considerar os seguros do setor aeronáutico e do setor de energia nuclear como uma das carteiras de seguro mais desequilibradas, tanto que os custos normalmente não são suportados apenas por uma única empresa de seguros. Uma possível solução apresentada é, além da possibilidade de resseguro, diminuir o valor dos prêmios de seguro aeronáutico. ${ }^{35}$

A respeito dos custos de capital e financiamentos, destaca-se que existe uma grande assimetria de informações na concessão de financiamentos e a defesa daqueles que financiam vêm como exigências de garantias. Alcançar as referidas garantias pode impedir que empresas com boas condições e disposição para realizar o repagamento dos financiamentos possam ter acesso aos mesmos. Dessa maneira, a dificuldade em ter acesso aos recursos do BNDES é um exemplo de motivo para elevar o custo de capital das companhias. Segundo os autores, essa situação acaba inibindo a competição na aviação regional brasileira. ${ }^{36}$

O último custo apresentado por Frederico Turolla, Maria Fernanda Lima e Thelma Ohira é o de manutenção das aeronaves, que estão relacionados aos elevados custos na importação de peças para reposição. ${ }^{37}$ Após visitar os principais custos apontados por alguns autores da economia dos transportes para a aviação regional, importa, nesse momento, apresentar o Programa de Aviação Regional e suas propostas para investimento nesse mercado específico.

\section{O PROGRAMA NACIONAL DE AVIAÇÃo REGIONAL: ENTRE A URGÊNCIA E A FICÇão}

No intuito de realizar investimentos no setor de infraestrutura, em agosto de 2012, o Governo Federal lançou o Programa de Investimento em Logística: Rodovias e Ferrovias. Ainda no mesmo ano, foi apresentado, também, um conjunto de políticas para o setor portuário e aeroportuário. Para esse último, três objetivos foram estabelecidos como principais: melhorar a qualidade dos serviços e a infraestrutura para os

34 RAGAZZO, Carlos Emmanuel Joppert; ALBUQUERQUE, Cristiane Landerdahl de. Concorrência e universalização: incentivos regulatórios à aviação regional. In: SILVA, Leandro Novais (Org.). Regulação e Concorrência no Setor Aéreo no Brasil: Alternativas Possíveis. São Paulo: Singular, 2014. p. 251.

35 TUROLLA, Frederico Araujo; LIMA, Maria Fernanda Freire; OHIRA, Thelma Harumi. Políticas públicas para a melhoria da competitividade da aviação regional brasileira. Journal of Transport Literature, v. 5, n. 4, p. 188-231, Oct. 2011. Disponível em: < http:// www.pesquisaemtransportes.net.br/relit/index.php/relit/article/view/jv5n4p11/pdf_57>. Acesso em: 1 set. 2015 . p. 218.

36 TUROLLA, Frederico Araujo; LIMA, Maria Fernanda Freire; OHIRA, Thelma Harumi. Políticas públicas para a melhoria da competitividade da aviação regional brasileira. Journal of Transport Literature, v. 5, n. 4, p. 188-231, Oct. 2011. Disponível em: <http:// www.pesquisaemtransportes.net.br/relit/index.php/relit/article/view/jv5n4p11/pdf_57>. Acesso em: 1 set. 2015 . p. 204.

37 TUROLLA, Frederico Araujo; LIMA, Maria Fernanda Freire; OHIRA, Thelma Harumi. Políticas públicas para a melhoria da competitividade da aviação regional brasileira. Journal of Transport Literature, v. 5, n. 4, p. 188-231, Oct. 2011. p. 204. Disponível em: <http://www.pesquisaemtransportes.net.br/relit/index.php/relit/article/view/jv5n4p11/pdf_57>. Acesso em: 1 set. 2015 . p. 228. 
usuários, ampliar a oferta de transporte aéreo à população brasileira e reconstruir a rede de aviação regional. No que tange à infraestrutura aeroportuária, o programa foi dividido em três etapas, a primeira foi a concessão dos aeroportos de Galeão (RJ) e Confins (MG); ${ }^{38}$ a segunda é o investimento de R $\$$ 7,3 bilhões em 270 aeroportos regionais; e a terceira é a indução na exploração comercial de aeroportos dedicados à aviação geral. ${ }^{39}$

A meta governamental com tal investimento na aviação regional é que $96 \%$ da população esteja a menos de $100 \mathrm{~km}$ de distância de um aeroporto apto a receber voos regulares. Os valores desse investimento viriam do Fundo Nacional de Aviação Civil, criado pela Lei no 12.462, de 4 de agosto de 2011, alterado pela Lei $n^{\circ}$ 12.648, de 17 de maio de 2012 e regulamentado pelo Decreto no 8.024, de 4 de junho de 2013. Em síntese, trata-se de fundo constituído por recursos decorrentes da receita de outorga recolhida pelos concessionários de aeroportos, do Adicional sobre Tarifa Aeroportuária (ATAERO) ${ }^{40}$, de parcela da Tarifa de Embarque Internacional (TEI) e de Recursos Próprios Financeiros (Rendimento de Aplicação Financeira). O Fundo Nacional de Aviação Civil tem como ações prioritárias a manutenção e aprimoramento da infraestrutura aeronáutica e aeroportuária pública. ${ }^{41}$

Em consonância com essa tentativa de fazer crescer o setor, o Governo Federal criou o projeto inicial do Programa de Desenvolvimento da Aviação Regional, por meio da Medida Provisória no 652, de 25 de julho de 2014. Os objetivos do programa eram: aumentar o acesso da população brasileira ao sistema aéreo de transporte; integrar comunidades isoladas à rede nacional de aviação civil; facilitar o acesso a regiões com potencial turístico; aumentar o número de municípios e rotas atendidos por transporte aéreo regular de passageiros; e aumentar o número de frequências das rotas regionais operadas regularmente. Para tanto, a União iria conceder subvenções para arcar com os custos das tarifas aeroportuárias e de navegação aérea para aeroportos regionais; pagar os valores do adicional de tarifa aeroportuária; e custear parte do montante gasto em voos nas rotas regionais. ${ }^{42}$

Acontece que a referida medida provisória teve o prazo de vigência encerrado no dia 24 de novembro de 2014, sem a respectiva conversão em lei. Apesar disso a comissão mista da Medida Provisória nº 656, de 7 de outubro de 2014, que tinha como relator o senador Romero Jucá (PMDB-RR), incorporou na íntegra o texto aprovado para a Medida Provisória no 652, após as alterações propostas pelo senador Flexa Ribeiro (PSDB-PA).${ }^{43}$ Comparando-se o texto proposto inicialmente pelo governo com a versão final, incorporada pela Medida Provisória no 656, que foi convertida na Lei 13.097, de 19 de janeiro de 2015, destacam-se quatro relevantes alterações.

A primeira é a definição mais específica de aeroporto regional, que seria aquele com movimentação anual inferior a 800.000 passageiros na Amazônia Legal e 600.000 nas demais regiões. A segunda é a autorização

38 De toda forma, vale ressaltar que o Governo Federal anunciou em junho de 2015 a concessão dos aeroportos Pinto Martins, Fortaleza (CE); Luiz Eduardo Magalhães, Salvador (BA); Hercílio Luz, Florianópolis (SC); e Salgado Filho, Porto Alegre (RS). BRASIL. Secretaria de Aviação Civil. Governo anuncia quatro novas concessões de aeroportos. Disponível em: < http://www.aviacao.gov.br/ noticias/2015/06/governo-anuncia-quatro-novas-concessoes-de-aeroportos>. Acesso em: 20 set. 2015.

39 PROGRAMA DE INVESTIMENTO EM LOGÍSTICA. Aeroportos. Disponível em: <http://www.logisticabrasil.gov.br/ aeroportos1>. Acesso em: 19 set. 2015.

40 Abaixo discute-se a possível extinção da ATAERO.

41 A arrecadação do Fundo Nacional de Aviação Civil em 2014 foi de“ $\mathrm{R} \$ 3.225,4$ milhões, sendo R \$ 1.459,9 milhões provenientes da receita de outorga recolhida pelos concessionários dos aeroportos de Campinas, Guarulhos, Confins, Galeão, Natal e Brasília; R\$ 1.118,7 milhões oriundos do Adicional sobre Tarifa Aeroportuária (ATAERO); R \$ 395,1 milhões da parcela da Tarifa de Embarque Internacional (TEI) e R \$251,7 milhões de Recursos Próprios Financeiros (Rendimento de Aplicação Financeira). A partir de 2016, o caixa do FNAC vai dar um salto com as concessões dos aeroportos de Porto Alegre, Florianópolis, Salvador e Fortaleza". (BRASIL. Secretaria da Aviação Civil. Fundo Nacional de Aviação Civil. Publicado em 4 jun. 2013. Disponível em: <http://www.aviacao.gov. $\mathrm{br} /$ acesso-a-informacao/acoes-e-programas/fundo-nacional-de-aviacao-civil>. Acesso em: 19 de set. 2015.)

42 Cf. BRASIL. Exposição de motivos da Medida Provisória no 652, de 25 de julho de 2014. Disponível em: <http://www.planalto.gov.br/ ccivil_03/_Ato2011-2014/2014/Exm/ExmMPv652-14.doc>. Acesso em: 1 set. 2015.

43 BRASIL. Senado Federal. Aprovado Programa de Desenvolvimento Regional. Brasília, 17 dez. 2014. Disponível em: <http://www12.senado. gov.br/noticias/materias/2014/12/18/aprovado-programa-de-desenvolvimento-da-aviacao-regional/tablet>. Acesso em: 19 set. 2015. 
para a União conceder subvenção de no máximo 30\% do Fundo Nacional de Aviação Civil. A terceira é o limite de custear até 60 passageiros transportados em voos diretos nas rotas regionais em função do aeroporto atendido, quantidade de quilômetros voados e do consumo de combustível, podendo ser subvencionados até 50\% dos assentos disponíveis por aeronave, exceto na Amazônia Legal, na qual não se aplica esse limite. A quarta e última é que esse programa tem duração de cinco anos, mas pode ser renovável por mais cinco, com o necessário embasamento técnico.

Frisa-se que a imprensa noticiou esse processo de incorporação do conteúdo da Medida Provisória $n^{\circ}$ 652 na de $n^{\circ} 656$ como uma articulação de congressistas do PMDB para a liberação da construção de aeroportos privados para voos comerciais. Sob a liderança do Deputado Federal Eduardo Cunha (PMDB-RJ), a intenção era viabilizar o Novo Aeroporto de São Paulo (Nasp), no município de Caieras/SP, idealizado pela Andrade Gutierrez e pela Camargo Corrêa. ${ }^{44}$ Entretanto, a Presidenta vetou o então art. 63-B, que versava sobre a possibilidade de outorga e aeródromos civis públicos sob regime de permissão. As razões apresentadas foram duas: i. os dispositivos criariam um desarranjo regulatório e ii. as medidas poderiam prejudicar o programa de incremento da aviação regional, em curso por meio do Programa de Aceleração do Crescimento - PAC. ${ }^{45}$

A “desnaturação do modelo setorial de exploração de infraestrutura aeroportuária” e o "desarranjo regulatório no setor" podem ser interpretados atrelados à valorização do modelo de concessão de aeródromos a iniciativa privada, com preservação das bases econômicas e financeiras das concessões aeroportos de Guarulhos, Galeão, Confins, Viracopos e Brasília. De toda sorte, o Programa de Desenvolvimento da Aviação Regional foi recebido com muito entusiasmo pelas empresas de aviação civil. Por exemplo, antes mesmo de sua aprovação, a Azul havia anunciado a ampliação da frota de aviões da Embraer. ${ }^{46}$ Em novembro de 2014, o presidente da Gol disse que o plano era positivo e abria oportunidades para a empresa. ${ }^{47}$

Apesar disso, o ano de 2015 foi marcado por muitas inseguranças quanto à efetividade do referido programa. Isso porque no final de 2014, o então Ministro Moreira Franco (PMDB/RJ) afirmava que os investimentos iriam ocorrer logo no início do ano seguinte e o que não aconteceu. ${ }^{48} \mathrm{Na}$ realidade, foi deflagrada uma intensa crise política e econômica no país, que, atrelada ao ajuste fiscal proposto pelo governo, freou os investimentos públicos em vários setores. Além disso, a própria mudança de ministro, Eliseu Padilha (PMDB/RS) no lugar de Moreira Franco (PMDB/RJ), foi vista por alguns como um ponto negativo na sequência das políticas púbicas para o setor.

No início de maio de 2015, em audiência pública no Senado para discutir o assunto, vários senadores afirmaram que o Programa de Aviação Regional era uma "peça de ficção". O ministro Eliseu Padilha, por sua vez, apontou que os recursos do Fundo Nacional de Aviação Civil não são atingidos pelos cortes orçamentários, de maneira que haverá continuidade nos investimentos públicos no setor. Na ocasião, ele aproveitou para informar que dos 270 aeroportos incluídos no programa 55 aguardam o licenciamento ambiental. ${ }^{49}$

44 LIMA, Vandson. Benefícios à aviação regional são retomados na MP 656. Valor Econômico, Brasília, 11 dez. 2014. Disponível em: <http://www8.valorinternational.com.br/politica/3812464/beneficios-aviacao-regional-sao-retomados-na-mp-656>. Acesso em: 20 set. 2015.

45 BRASIL. Mensagem de veto da Lei no 13.097, de 19 de janeiro de 2015. Disponível em: <http://www.planalto.gov.br/ccivil_03/_ato2015-2018/2015/Msg/VEP-21.htm>. Acesso em: 1 set. 2015.

46 OLIVEIRA, João José; MARCHESINI, Lucas. Azul ampliará frota com apoio à aviação regional. Valor Econômico, São Paulo, 30 jul. 2014. Disponível em: <http://www.valor.com.br/brasil/3631532/azul-ampliara-frota-com-apoio-aviacao-regional>. Acesso em: 21 set. 2015.

47 OLIVEIRA, João José. 'Plano regional é oportunidade para a Gol', diz presidente da empresa. Valor Econômico, São Paulo, 12 nov. 2014. Disponível em: <http://www.valor.com.br/empresas/3776300/plano-regional-e-oportunidade-para-gol-diz-presidenteda-empresa>. Acesso em: 19 set. 2015.

48 BRASIL. Secretaria da Aviação Civil. Aviação regional terá subsídio a partir de 2015. Brasília, 29 jul. 2014. Disponível em: <http:// www.aviacao.gov.br/noticias/2014/07/aviacao-regional-tera-subsidio-a-partir-de-2015 >. Acesso em: 21 set. 2015.

49 BAPTISTA, Rodrigo. Programa de aviação regional ainda é 'peça de fição', diæem senadores em audiência. Brasília: Senado Federal, 6 maio 2015. Disponível em: <http://www12.senado.leg.br/noticias/materias/2015/05/06/programa-de-aviacao-regional-ainda-e-pecade-ficcao-dizem-senadores-em-audiencia>. Acesso em: 21 set. 2015. 
A problemática do licenciamento ambiental só foi solucionada com a Resolução do Conselho Nacional do Meio Ambiente (CONAMA) de no 470, de 27 de agosto de 2015. Ela dispõe sobre a regularização ambiental dos aeroportos regionais que já estão em operação; o licenciamento ambiental para ampliação de aeroportos regionais; e o licenciamento ambiental para novos aeroportos regionais. Para tanto, ela reproduziu o critério legal para definir se um aeroporto é regional, qual seja, ter movimentação anual inferior a 800.000 passageiros por ano, quando localizado na Amazônia Legal, e menos de 600.000 passageiros por ano nas demais regiões. A intenção dessa resolução é padronizar os procedimentos e simplificá-los com o objetivo de diminuir a demora da análise do licenciamento de 2 anos para 6 meses. Essa preocupação ganha especial relevância se for levado em consideração que apenas $8 \%$ dos 270 aeroportos contemplados no programa de aviação regional têm licenciamento regularizado. ${ }^{50}$

De toda sorte, a demora para dar seguimento às políticas públicas de desenvolvimento da aviação regional, decorrente da fragilidade política e econômica do país, gerou uma inquestionável insegurança a algumas empresas do setor. A Azul, por exemplo, comprou 125 aviões em 2014 e planejava comprar mais 20 no ano de 2015, mas desistiu pela demora na efetividade do referido programa, especialmente no que tange aos subsídios, que aguardam regulamentação. ${ }^{51}$

Além dessa questão de infraestrutura e de subsídios, outro ponto controvertido reiteradamente apresentado como solução para ampliar os investimentos no setor é a flexibilização da quantidade de capital estrangeiro em empresas aéreas brasileiras. Nesse contexto, a comissão de especialistas que foi instaurada para apresentar o anteprojeto de reforma do Código Brasileiro de Aeronáutica debate, dentre outras reformas, a possibilidade alterar o art. 181 do referido documento legal, que dispõe sobre as condições da concessão para serviços aéreos públicos. ${ }^{52}$

A redação original do dispositivo determinava que os serviços aéreos públicos somente poderiam ser concedidos ou autorizados à pessoa jurídica brasileira, com sede no Brasil; com, pelo menos, quatro quintos do capital com direito a voto pertencentes a brasileiros; e com direção confiada exclusivamente a brasileiros. Além disso, de acordo com o $\int 4^{\circ}$, "Desde que a soma final de ações em poder de estrangeiros não ultrapasse o limite de $1 / 5$ (um quinto) do capital, poderão as pessoas estrangeiras, naturais ou jurídicas, adquirir ações do aumento de capital".

Paralelamente às discussões de reformar do Código Brasileiro de Aeronáutica, ocorridas no âmbito legislativo, foi editada a já mencionada Medida Provisória no 714 , de $1^{\circ}$ de março de 2016, que modificou a redação do art. 181 do referido Código.

A nova redação flexibiliza a exigência de composição de capital das concessionárias ou autorizatárias, exigindo que "pelo menos 51\% (cinquenta e um por cento) do capital com direito a voto pertencente a bra-

50 RITTNER, Daniel. Resolução acelera licença ambiental para aeroportos. Valor Econômico, Brasília, 14 ago. 2015. Disponível em: <http://www.valor.com.br/brasil/4179582/resolucao-acelera-licenca-ambiental-para-aeroportos>. Acesso em: 26 set. 2015.

51 GALLO, Ricardo. Azul e Gol esperam plano de aviação regional, enquanto TAM já cria voos. Folha de São Paulo, São Paulo, 31 ago. 2015. Disponível em: <http://www1.folha.uol.com.br/mercado/2015/08/1675651-azul-e-gol-esperam-plano-de-aviacao-regional-enquanto-tam-ja-cria-voos.shtml>. Acessado em: 26 set. 2015.

52 A referida comissão é presidida por Georges de Moura Ferreira, professor de Direito Aeronáutico e aviador, e tem como relatora a Professora de Direito Internacional e Doutora em Direito Espacial Maria Helena Fonseca. Ela foi instaurada no dia 16 de novembro de 2015 e teve como prazo final o dia 12 de dezembro de 2015. Dentre as principais discussões desenvolvidas pelas Comissão, destaca-se reunião ocorrida em 14 de setembro de 2015, na qual Fernando Soares Vieira, representante da Comissão de Valores Mobiliários, discorreu sobre os arranjos societários que, na prática, possibilitam capitalização estrangeira maior que o limite previsto em lei. De acordo com ele, desde 2001, a proporção entre ações ordinárias e preferenciais nas companhias de capital aberto é de $50 \%$ para cada espécie. Entretanto, para conseguir maiores investimentos estrangeiros, as empresas passaram a garantir vantagens extras às novas emissões de papéis preferenciais. Fernando Soares Vieira afirmou que esse tipo de organização societária pode dificultar a fiscalização da CVM, pois não se aplica à Lei de Sociedades Anônimas. Ele citou como exemplo a TAM, que, depois que fundiu com a LAN, obteve registro na CVM como empresa estrangeira. Naquele contexto realizou-se propostas de duas possíveis soluções para redação do art. 181 do Código de Aeronáutica: uma de limitar a 49\% das ações para estrangeiros e outra de possibilitar empresas aéreas com $100 \%$ do capital estrangeiro. 
sileiros, prevalecendo essa limitação nos eventuais aumentos do capital social". O limite poderá ser diminuído nos termos do novo $\int 5^{\circ}$ do art. 181, que dispõe que, desde que "observada a reciprocidade, os acordos sobre serviços aéreos celebrados pela República Federativa do Brasil poderão prever limite de capital social votante em poder de brasileiros inferior ao mínimo estabelecido no inciso II do caput, com validade apenas entre as partes contratantes". Foi igualmente excluída a exigência de que a direção das concessionárias ou autorizatárias seja confiada exclusivamente a brasileiros.

A limitação de capital estrangeiro permite maior capitalização das empresas brasileiras, sem perder de vista o desenvolvimento destas, que, em última instância consolidam o desenvolvimento e apropriação de inovações tecnológicas para o país, elemento central para a diminuição da dependência da economia do Brasil. As alterações previstas pela Medida Provisória nº 714, de $1^{\circ}$ de março de 2016 mantém referida limitação de capital estrangeiro, apesar de ter ampliado a sua margem de participação.

Além desse aspecto, outra medida que tem como objetivo desenvolver o setor foi apresentada por Daniel Alves da Cunha, representante do setor de regulação da ANAC, a possibilidade de flexibilização da regulamentação nos aeroportos. Em síntese, o que se propõe é que seja reduzida a burocracia visando à atração de empresas e novas linhas em aeroportos de menor movimento operacional, levando-se em consideração, também, o padrão de riscos de cada aeródromo. ${ }^{53}$

É preciso alinhar todas essas questões à operacionalização das outorgas aeroportuárias, cuja regulamentação é atualmente feita pela Portaria SAC nº 183, de 10 de setembro de 2014. O veto aos art. 123 e 124 não pode ser interpretado como absoluta vedação à realização de outorgas de aeroportos regionais. Destaca-se, por exemplo, a recente autorização para concessão do aeroporto de Comandatuba. O Estado da Bahia é delegatário desse aeródromo desde 2014 e com a autorização conferida pela Portaria no 9 de 22 de janeiro de 2016 da Secretaria de Aviação Civil poderá conceder a exploração do terminal à iniciativa privada.

A Secretaria de Aviação $0^{54}$ noticia que outros aeródromos já possuem processos a exploração à iniciativa privada sendo eles Amarais, Araras, Bragança Paulista, Guarujá, Itanhaém, Jundiaí e Ubatuba, no Estado de São Paulo, Caldas Novas (GO), Zona da Mata (MG) e Campos dos Goytacazes (RJ). A Secretaria indica ainda que mais seis localidades receberão a anuência para concessão entre elas: Barreiras, Caravelas e Teixeira de Freitas, na Bahia; Pouso Alegre e São Lourenço, em Minas Gerais; e Anápolis, em Goiás.

A existência desses projetos evidencia que apesar da crise e das restrições orçamentárias dela derivadas, há um cenário de possibilidade de desenvolvimento de projetos com a participação dos agentes privados. Por óbvio essa participação não supre a necessidade de realização de investimentos públicos, sobretudo nos casos em que a modelagem econômica dos projetos não evidencia taxa de atratividade suficiente para viabilizar a concessão dos aeródromos.

Nesse contexto, mesmo em meio as incertezas políticas e econômicas do país em 2015, cumpre ressaltar que o estado da Bahia e do Rio de Janeiro possuem planos avançados para impulsionar a aviação regional. Para tanto, o Governo baiano reduziu a alíquota do Imposto sobre Circulação de Mercadorias e Serviços (ICMS) sobre o querosene de aviação, em algumas situações, de 17\% a 7\%. Além disso, prevê-se a construção de um novo aeroporto em Vitória da Conquista com verbas federais e estaduais. No Rio de Janeiro, por sua vez, o ponto principal é construir o aeroporto do Vale do Aço, entre Volta Redonda e Piraí. ${ }^{55}$ Todavia o que se percebe é que, apesar dos esforços em sinalizar avanços nesse programa de investimento na aviação regional, existe uma substancial diminuição do ritmo de investimentos públicos, tal qual foi previsto e sina-

53 BRASIL. Senado Federal. Comissão discute aumento do capital estrangeiro em empresas aéreas. Brasília, 14 set. 2015. Disponível em: <http://www12.senado.leg.br/noticias/materias/2015/09/14/comissao-discute-aumento-do-capital-estrangeiro-em-empresasareas $>$. Acesso em: 20 set. 2015.

54 BRASIL. Secretaria de Aviação Civil. Aeroporto de Comandatuba é autorizado para concessão. Brasília, 25 jan. 2016 <http://www. aviacao.gov.br/noticias/2016/01/aeroporto-de-comandatuba-e-autorizado-para-concessao >. Acesso em: 14 mar. 2016.

55 ZAPAROLLI, Domingos. Bahia e Rio têm planos avançados. Valor Econômico, São Paulo, 10 ago. 2015. Disponível em: <http:// www8.valorinternational.com.br/empresas/4171878/bahia-e-rio-tem-planos-avancados >. Acessado em: 26 ago. 2015. 
lizado às empresas do setor no final de 2014.

Resta a esperança de que tal ritmo de investimentos se recupere, seja pela boa administração do Fundo Nacional de Aviação Civil e efetivação das subvenções econômicas para empresas participantes do Programa de Desenvolvimento da Aviação Regional, como previsto no art. 117 da Lei 13.097/2015, seja pelo desenvolvimento de mecanismo de outorga aeroportuária que possibilitem o ingresso de capital privado na gestão dos aeroportos regionais.

\section{Considerações finais}

O presente estudo permitiu concluir que a aviação regional tem relevância estratégica para o desenvolvimento econômico do Brasil. Isso decorre tanto do seu potencial de fomentar a concorrência no setor aéreo, quando da geração de empregos e promoção da sustentação das diversas economias regionais. Para tanto, o Estado brasileiro deve reformular o seu modelo de intervenção para reduzir a contração da aviação regional no país.

Conforme visto, várias medidas são propostas por teóricos da economia dos transportes e da regulação econômica. As mais relevantes e adequadas estão no campo do direito da concorrência, tributário, regulatório, econômico. Diante desse contexto, ganha especial relevância os desafios políticos, econômicos e jurídicos do Programa Nacional de Aviação Regional, lançado pelo Governo Federal em 2012.

Em síntese, constata-se que a aviação regional é um setor que tem ganhado uma especial atenção do Governo Federal nos últimos anos, o que se percebe ao fazer o levantamento das concessões de infraestrutura no setor. Apesar disso, a crise política e econômica do país impede uma saída mais consistente para o estrangulamento da aviação regional no país, colocando em xeque essa dimensão da economia, que central para o desenvolvimento do país.

\section{REFERÊNCIAS BIBLIOGRÁFICAS}

ASSOCIAÇÃO BRASILEIRA DAS EMPRESAS AÉREAS. Aviação brasileira: Agenda 2020, Brasília: ABEAR, 2014. p. 29-30. Disponível em: <http://www.abear.com.br/uploads/pdf/releases/agenda2020.pdf>. Acesso em: 2 set. 2015.

BAPTISTA, Rodrigo. Programa de aviação regional ainda é 'peça de fiçãao', dižem senadores em andiência. Brasilia: Senado Federal, 6 maio 2015. Disponível em: <http:/ /www12.senado.leg.br/noticias/materias/2015/05/06/ programa-de-aviacao-regional-ainda-e-peca-de-ficcao-dizem-senadores-em-audiencia $>$. Acesso em: 21 set. 2015.

BETTINI, Humberto Filipe; OLIVEIRA, Alessandro V. M. Transporte aéreo regional: entre economias de escala e custos de transação. Journal of Transport Literature, v. 5, n. 4, p. 171-187, Oct. 2011. Disponível em: $<$ https: $/ /$ www.google.com.br/url? sa $=\mathrm{t} \& \mathrm{rct}=\mathrm{j} \& \mathrm{q}=\&$ esrc $=\mathrm{s} \&$ source $=$ web\&cd $=1 \& \mathrm{cad}=\mathrm{rja} \& u a c t=8 \& v e d=$ 0CBwQFjAAahUKEwiW5e_klMDIAhWIth4KHeYVB0c\&url=http $\% 3 \mathrm{~A} \% 2 \mathrm{~F} \% 2 \mathrm{Fwww}$.pesquisaemtransportes.net.br $\% 2$ Frelit $\% 2$ Findex.php $\% 2$ Frelit $\% 2$ Farticle $\% 2$ Fdownload $\% 2 F j v 5 n 4 p 10 \% 2 F 135 \&$ usg=AFQj CNG1IqNxCI-1hoekrUSxBNxUymmI8Q\&sig2=ZPwA68Bu_OzMku67dsOwyg\&bvm=bv.104819420,d. dmo>. Acesso em: 1 set. 2015.

BETTINI, Humberto. Um retrato da aviação regional no Brasil. Journal of Transport Literature, v. 1, n. 1, p. 46-65, jan. 2007. Disponível em: < http://pesquisaemtransportes.net.br/relit/index.php/relit/article/ viewFile/11/70>. Acesso em: 1 set. 2015. 
BANCO NACIONAL DO DESENVOLVIMENTO. Aviação regional brasileira: modal aéreo IV. Informe infra-estrutura, n. 50, p. 7, 2002. Disponível em: <http://www.bndes.gov.br/SiteBNDES/export/sites/default/bndes_pt/Galerias/Arquivos/conhecimento/infra/Inf02-50.pdf>. Acesso em: 28 de ago. 2015.

BRASIL. Exposição de motivos da Medida Provisória nº 652, de 25 de julho de 2014. Disponível em: <http:/ /www. planalto.gov.br/ccivil_03/_Ato2011-2014/2014/Exm/ExmMPv652-14.doc>. Acesso em: 1 set. 2015.

BRASIL. Mensagem de veto da Lei no 13.097, de 19 de janeiro de 2015. Disponível em: <http://www.planalto.gov.br/ccivil_03/_ato2015-2018/2015/Msg/VEP-21.htm>. Acesso em: 1 set. 2015.

BRASIL. Secretaria da Aviação Civil. Aviação regional terá subsídio a partir de 2015. Brasília, 29 jul. 2014. Disponível em: <http://www.aviacao.gov.br/noticias/2014/07/aviacao-regional-tera-subsidio-a-partirde-2015>. Acesso em: 21 set. 2015.

BRASIL. Secretaria de Aviação Civil. Governo anuncia quatro novas concessões de aeroportos. Disponível em: <http://www.aviacao.gov.br/noticias/2015/06/governo-anuncia-quatro-novas-concessoes-de-aeroportos>. Acesso em: 20 set. 2015.

BRASIL. Secretaria de Aviação Civil. Aeroporto de Comandatuba é autorizado para concessão. Brasília, 25 jan. 2016 <http://www.aviacao.gov.br/noticias/2016/01/aeroporto-de-comandatuba-e-autorizado-para-concessao >. Acesso em: 14 mar. 2016.

BRASIL. Secretaria de Aviação Civil. Fundo Nacional de Aviação Civil. Publicado em 4 jun. 2013. Disponível em: $\quad<$ http://www.aviacao.gov.br/acesso-a-informacao/acoes-e-programas/fundo-nacional-de-aviacaocivil>. Acesso em: 19 de set. 2015.

BRASIL. Senado Federal. Aprovado Programa de Desenvolvimento Regional. Brasília, 17 dez. 2014. Disponível em: <http://www12.senado.gov.br/noticias/materias/2014/12/18/aprovado-programa-de-desenvolvimentoda-aviacao-regional/tablet>. Acesso em: 19 set. 2015.

BRASIL. Senado Federal. Comissão discute aumento do capital estrangeiro em empresas aéreas. Brasília, 14 set. 2015. Disponível em: < http://www12.senado.leg.br/noticias/materias/2015/09/14/comissao-discute-aumentodo-capital-estrangeiro-em-empresas-areas >. Acesso em: 20 set. 2015.

CAMAROTTO, Murillo; IZAGUIRRE, Mônica. Exploração comercial de aeroportos em regime de autorização é vetada. Valor Econômico, Brasília, 20 jan. 2015. Disponível em: <http://www.valor.com.br/brasil/3868062/exploracao-comercial-de-aeroportos-em-regime-de-autorizacao-e-vetada $>$. Acesso em: 20 set. 2015.

CAVES, Douglas; CHRISTENSEN, Laurits; TRETHEWAY, Michael. Economies of density versus economies of scale: why trunk and local airline costs differ? Rand Journal of Economics, v. 15, p. 471-489, 1984. Disponível em: <http://econpapers.repec.org/scripts/redir.pf?u=http\%3A\%2F\%2Flinks.jstor. org\%2Fsici\%3Fsici\%3D0741-6261\%2528198424\%252915\%253A4\%253C471\%253AEODVEO\%253E2. 0.CO\%253B2-S\%26origin\%3Drepec;h=repec:rje:randje:v:15:y:1984:i:winter:p:471-489>. Acesso em: 1 set. 2015.

DEMANT, Marcos Alexandre. Infraestrutura aeroportuária e o desenvolvimento do tráfego aéreo regional no Brasil. Journal of Transport Literature, v. 5, n. 1, p. 124-160, Jan. 2011. Disponível em: <https://www. google.com.br $/$ url? sa $=t \& r c t=j \& q=\& e s r c=s \&$ source $=$ web\&cd $=1 \& \mathrm{cad}=$ rja\&uact $=8 \& v e d=0 \mathrm{CBwQFjA}$ AahUKEwiCkceZn8DIAhWIVh4KHa1XAQs\&url=http $\% 3 \mathrm{~A} \% 2 \mathrm{~F} \% 2 \mathrm{Fwww}$.pesquisaemtransportes.net. br $\% 2$ Frelit $\% 2$ Findex.php $\% 2$ Frelit $\% 2$ Farticle $\% 2$ Fdownload $\% 2 F j v 5 n 1 p 7 \% 2 F 83 \& u s g=A F Q j C N E o d E 0 M$ g9BV9erZMWira_tijZVSjw\&sig2=FuuWkoz1LyJhSso3xW4bOw\&bvm=bv.104819420,d.dmo>. Acesso em: 1 set. 2015.

GALLO, Ricardo. Azul e Gol esperam plano de aviação regional, enquanto TAM já cria voos. Folha de São Paulo, São Paulo, 31 ago. 2015. Disponível em: <http://www1.folha.uol.com.br/mercado/2015/08/1675651- 
azul-e-gol-esperam-plano-de-aviacao-regional-enquanto-tam-ja-cria-voos.shtml>. Acessado em: 26 set. 2015.

INSTITUTO DE PESQUISA ECONÔMICA APLICADA. Mangabeira Unger toma posse como novo ministro da SAE. Brasília, 2 fev. 2015. Disponível em: <http://www.ipea.gov.br/portal/index.php?option=com_ content\&view $=$ article\&id $=24432>$. Acesso em: 2 set. 2015.

LEURQUIN, Pablo. Os impactos da regulação da aviação civil na integração inter-regional do Brasil. 2013. Dissertação (Mestrado) - Universidade Federal de Minas Gerais, Belo Horizonte, 2013.

LIMA, Vandson. Benefícios à aviação regional são retomados na MP 656. Valor Econômico, Brasília, 11 dez. 2014. Disponível em: < http://www8.valorinternational.com.br/politica/3812464/beneficios-aviacaoregional-sao-retomados-na-mp-656>. Acesso em: 20 set. 2015.

OLIVEIRA, Alessandro; SALGADO, Lúcia Helena. Constituição do marco regulatório para o mercado brasileiro de aviação regional. abr. 2008. Disponível em: <http://pantanalbraziltourism.com/fotos/arquivos/96.pdf>. Acesso em: 1 set. 2015.

OLIVEIRA, Alessandro; SALGADO, Lúcia Helena. Popularização do transporte aéreo no Brasil: onde falta avançar nas políticas públicas? In: SILVA, Leandro Novais (Org.). Regulação e concorrência no setor aéreo no Brasil: alternativas possíveis. São Paulo: Singular, 2014.

OLIVEIRA, João José. 'Plano regional é oportunidade para a Gol', diz presidente da empresa. Valor Econômico, São Paulo, 12 nov. 2014. Disponível em: <http://www.valor.com.br/empresas/3776300/plano-regionale-oportunidade-para-gol-diz-presidente-da-empresa>. Acesso em: 19 set. 2015.

OLIVEIRA, João José; MARCHESINI, Lucas. Azul ampliará frota com apoio à aviação regional. Valor Econômico, São Paulo, 30 jul. 2014. Disponível em: < http://www.valor.com.br/brasil/3631532/azul-ampliara-frota-com-apoio-aviacao-regional>. Acesso em: 21 set. 2015.

PINTO, Victor Carvalho. Dirigismo versus livre-iniciativa na regulação econômica do transporte aéreo. In: SILVA, Leandro Novais (Org.). Regulação e concorrência no setor aéreo no Brasil: alternativas possíveis. São Paulo: Singular, 2014.

PROGRAMA DE INVESTIMENTO EM LOGÍSTICA. Aeroportos. Disponível em: < http://www.logisticabrasil.gov.br/aeroportos1>. Acesso em: 19 set. 2015.

RÁDIO CÂMARA. Mangabeira Unger explica ações do governo para Amazônia e desenvolvimento regional. Câmara dos Deputados, Brasilia, 10 mar. 2009. (3'57'). Disponível em: <http://www2.camara.leg.br/ camaranoticias/radio/materias/ULTIMAS-NOTICIAS/364792-MANGABEIRA-UNGER-EXPLICA-A $\%$ C3\%87\%C3\%95ES-DO-GOVERNO-PARA-AMAZ $\%$ C3\%94NIA-E-DESENVOLVIMENTO-REGIONAL-(03'57\%22).html>. Acesso em: 2 de set. 2015.

RAGAZZO, Carlos Emmanuel Joppert; ALBUQUERQUE, Cristiane Landerdahl de. Concorrência e universalização: incentivos regulatórios à aviação regional. In: SILVA, Leandro Novais (Org.). Regulação e concorrência no setor aéreo no Brasil: alternativas possíveis. São Paulo: Singular, 2014.

RITTNER, Daniel. Resolução acelera licença ambiental para aeroportos. Valor Econômico, Brasília, 14 ago. 2015. Disponível em: < http://www.valor.com.br/brasil/4179582/resolucao-acelera-licenca-ambiental-para-aeroportos>. Acesso em: 26 set. 2015.

ROSEMAIN, Mathieu. Grevistas agridem executivos da Air France. Valor Econômico, São Paulo, 6 out. 2015. Disponível em: <http://www.valor.com.br/empresas/4257122/grevistas-agridem-executivos-da-air-france>. Acesso em: 8 out. 2015.

RUIZ, Ricardo Machado; HECKTHEUER, Leticiá Monteiro; BARROS, Gabriel Gil Barreto. Concentração e rivalidade em transporte aéreo de passageiros: reflexões a partir de casos recentes. In: SILVA, Le- 
andro Novais (Org.) Regulação e concorrência no setor aéreo no Brasil: alternativas possíveis. São Paulo: Singular, 2014. p. 201-230.

TUROLLA, Frederico Araujo; LIMA, Maria Fernanda Freire; OHIRA, Thelma Harumi. Políticas públicas para a melhoria da competitividade da aviação regional brasileira. Journal of Transport Literature, v. 5, n. 4, p. 188-231, Oct. 2011. Disponível em: <http://www.pesquisaemtransportes.net.br/relit/index.php/relit/ article/view/jv5n4p11/pdf_57>. Acesso em: 1 set. 2015.

ZAPAROLLI, Domingos. Bahia e Rio têm planos avançados. Valor Econômico, São Paulo, 10 ago. 2015. Disponível em: <http://www8.valorinternational.com.br/empresas/4171878/bahia-e-rio-tem-planos-avancados>. Acessado em: 26 ago. 2015. 
Para publicar na revista Brasileira de Políticas Públicas, acesse o endereço eletrônico www.rbpp.uniceub.br

Observe as normas de publicação, para facilitar e agilizar o trabalho de edição. 